\title{
Regional differences in cellular mechanisms of adipose tissue gain with overfeeding
}

\author{
Yourka D. Tchoukalova, ${ }^{a, b}$, Susanne B. Votruba ${ }^{a}$, Tamara Tchkonia ${ }^{c}$, Nino Giorgadzec, James L. Kirkland', \\ and Michael D. Jensen ${ }^{a, 1}$
}

${ }^{\mathrm{a} E n d o c r i n e ~ R e s e a r c h ~ U n i t ~ a n d ~}{ }^{\mathrm{C} R o b e r t}$ and Arlene Kogod Center on Aging, Mayo Clinic, Rochester, MN 55905; and ${ }^{\mathrm{b}}$ Pennington Biomedical Research Center, Baton Rouge, LA 70808

Edited by Gerald I. Shulman, Howard Hughes Medical Institute and Yale University, New Haven, CT, and approved September 8, 2010 (received for review April 19, 2010)

\begin{abstract}
Body fat distribution is an important predictor of the metabolic consequences of obesity, but the cellular mechanisms regulating regional fat accumulation are unknown. We assessed the changes in adipocyte size (photomicrographs) and number in response to overfeeding in upper- and lower-body s.c. fat depots of 28 healthy, normal weight adults ( $15 \mathrm{men}$ ) age $29 \pm 2 \mathrm{y}$. We analyzed how these changes relate to regional fat gain (dual energy X-ray absorptiometry and computed tomography) and baseline preadipocyte proliferation, differentiation [peroxisome proliferator-activated receptor$\gamma 2$ (PPAR $\gamma 2$ ) and CCAAT/enhancer binding protein- $\alpha$ (C/EBP $\alpha$ ) mRNA]), and apoptotic response to TNF- $\alpha$. Fat mass increased by $1.9 \pm 0.2 \mathrm{~kg}$ in the upper body and $1.6 \pm 0.1 \mathrm{~kg}$ in the lower body. Average abdominal s.c. adipocyte size increased by $0.16 \pm 0.06 \mu \mathrm{g}$ lipid per cell and correlated with relative upper-body fat gain ( $r=$ $0.74, P<0.0001)$. However, lower-body fat responded to overfeeding by fat-cell hyperplasia, with adipocyte number increasing by $2.6 \pm 0.9 \times 10^{9}$ cells $(P<0.01)$. We found no depot-differences in preadipocyte replication or apoptosis that would explain lowerbody adipocyte hyperplasia and abdominal s.c. adipocyte hypertrophy. However, baseline PPAR 2 and C/EBP $\alpha$ mRNA were higher in abdominal than femoral s.c. preadipocytes $(P<0.005$ and $P<0.03$, respectively), consistent with the ability of abdominal s.c. adipocytes to achieve a larger size. Inherent differences in preadipocyte cell dynamics may contribute to the distinct responses of different fat depots to overfeeding, and fat-cell number increases in certain depots in adults after only 8 wk of increased food intake.
\end{abstract}

adipocyte | bodycomposition | body fat gain | fat distribution | preadipocyte

A ccumulation of fat in upper-body/visceral adipose tissue and ectopic sites, including muscle and the liver, is associated with insulin resistance and obesity-related metabolic abnormalities (1), whereas preferential lower-body fat gain seems to have a protective effect (2-4). Thus, the mechanism(s) by which expansion of some depots occurs at the expense of others is of considerable interest. Recently, it has been suggested that fat-cell number remains stable after approximately age $20 \mathrm{y}$, implying that fat gain during adulthood is the result of adipocyte hypertrophy, not hyperplasia (5). If so, fat gain and body fat distribution would depend entirely on regional fat-cell number before age $20 \mathrm{y}$ and extent of adipocyte hypertrophy. These conclusions, however, were based on measurements of abdominal s.c. fat-cell size (5), but fat-cell progenitors from different body-fat depots have distinct properties (6-8). Thus, we were reluctant to accept the tenet that adults do not develop new adipocytes with weight gain. To test whether different fat-tissue depots vary with respect to cellular mechanisms of fat enlargement, we analyzed different adipose tissue beds in individuals longitudinally.

Upper-body and lower-body s.c. fat account for the vast majority of total body fat in normal-weight adults (9). These depots differ in fatty acid storage (10) and release characteristics (11). Thus, we investigated whether these two major depots differ in their capacity for increasing fat-cell number in response to overfeeding and, if so, whether we could identify characteristics of preadipocytes that might contribute to regional differences in fat-depot growth. To investigate these questions, we induced a small total body-fat gain $(\sim 4 \mathrm{~kg})$ in volunteers. We measured changes in fat mass in visceral and upper- and lower-body s.c. depots as well as changes in s.c. fatcell size and number. We assessed cell-dynamic properties of preadipocytes at baseline. Our results indicate that upper- and lower-body s.c. fat differs remarkably in the mechanisms by which fat gain occurs, in part, because of inherent differences in the characteristics of preadipocyte cell dynamics.

\section{Results}

Effect of Overfeeding on Body Composition and Body Fat Distribution. By design, body weight increased by $4.6 \pm 2.2 \mathrm{~kg}$ (from $66.5 \pm 4.4$ to $71.1 \pm 2.5 \mathrm{~kg}$ ), leading to an increase in body mass index (BMI) of $1.5 \pm 0.1 \mathrm{~kg} / \mathrm{m}^{2}$ (from $22.1 \pm 0.5$ to $23.6 \pm 0.5 \mathrm{~kg} / \mathrm{m}^{2}$ ). This weight gain in both men and women resulted from an increase in fat tissue (3.8 $\pm 0.3 \mathrm{~kg}$ of fat gained, $P=0.0007)$, because fat-free mass remained unchanged (Table 1 ).

Effect of Overfeeding on Adipocyte Size and Number. The effects of overfeeding on regional adipose cellularity are presented in Table 2. On average, the size but not the number of abdominal s.c. adipocytes increased significantly in response to fat gain $(P=0.001)$. The change in abdominal s.c. adipocyte size was related negatively to baseline size in women but not in men (Fig. 1A). Thus, women with the smaller abdominal s.c. adipocytes gained abdominal fat largely via adipocyte hypertrophy, whereas women with an average adipocyte size (in excess of $\sim 0.50 \mu \mathrm{g}$ lipid per cell) must have recruited new, smaller adipocytes for the average size of mature adipocytes to decrease. Virtually all men increased abdominal adipocyte size irrespective of baseline size. Histograms of adipocyte size from the woman with the greatest decrease and the man with the greatest increase in abdominal adipocyte size are provided in Fig. S1. There was no statistical evidence for two populations of mature adipocytes. The woman with the greatest decrease in the average size of abdominal adipocytes (F1) had a decrease in the proportion of larger cells. We found a significant relationship between the change in abdominal s.c. adipocyte size and percent of fat gain in the upper-body s.c. depot $(r=0.74, P<0.0001)$ (Fig. $2 A$ ), indicating that the increase in abdominal adipocyte size accounted for the increase in abdominal s.c. fat mass.

On average, femoral s.c. adipocyte size remained unchanged in the face of increased leg fat, whereas overfeeding resulted in a significant $(P=0.004)$ increase in lower-body adipocyte number (Table 2). As with abdominal adipocytes, however, the change in Author contributions: J.L.K. and M.D.J. designed research; Y.D.T., S.B.V., T.T., and N.G.
performed research; Y.D.T., T.T., J.L.K., and M.D.J. analyzed data; and Y.D.T., S.B.V., T.T.,
J.L.K., and M.D.J. wrote the paper.
The authors declare no conflict of interest.
This article is a PNAS Direct Submission.
${ }^{1}$ To whom correspondence should be addressed. E-mail: jensen@mayo.edu.
This article contains supporting information online at www.pnas.org/lookup/suppl/doi:10 1073/pnas. 1005259107/-/DCSupplemental. 
Table 1. Effect of overfeeding on body composition and regional fat mass

\begin{tabular}{|c|c|c|c|c|c|c|c|c|c|c|c|}
\hline \multirow[b]{2}{*}{ Variable } & \multicolumn{2}{|c|}{ Women $(n=13)$} & \multicolumn{2}{|c|}{ Men $(n+15)$} & \multicolumn{3}{|c|}{$P$ value } & \multirow{2}{*}{$\begin{array}{c}\Delta, \text { absolute: } \\
\text { all* or } \\
\text { women/men }\end{array}$} & \multirow{2}{*}{$\begin{array}{l}P \text { value } \\
\text { for sex }\end{array}$} & \multirow{2}{*}{$\begin{array}{l}\Delta, \text { relative to } \\
\text { baseline }(\%) \text { : } \\
\text { all* or } \\
\text { women/men }\end{array}$} & \multirow{2}{*}{$\begin{array}{l}P \text { value } \\
\text { for sex }\end{array}$} \\
\hline & Pre & Post & Pre & Post & Sex & Time & $\mathrm{S} \times \mathrm{T}$ & & & & \\
\hline Fat-free mass $(\mathrm{kg})$ & $39.1 \pm 1.7$ & $39.8 \pm 1.6$ & $64.1 \pm 1.6$ & $64.9 \pm 1.6$ & $<0.0001$ & 0.6 & 0.95 & $0.8 \pm 0.2$ & 0.7 & $1.7 \pm 0.5$ & 0.7 \\
\hline Total fat mass $(\mathrm{kg})$ & $16.1 \pm 1.0$ & $19.3 \pm 1.0$ & $12.3 \pm 0.9$ & $16.6 \pm 1.0$ & 0.002 & 0.0007 & 0.6 & $3.8 \pm 0.3$ & 0.1 & $20.9 \pm 1.8 / 37.6 \pm 5.7$ & 0.01 \\
\hline $\begin{array}{l}\text { Total fat mass/ } \\
\text { body weight (\%) }\end{array}$ & $29.5 \pm 1.7$ & $33.0 \pm 1.6$ & $16.1 \pm 1.1$ & $20.5 \pm 1.1$ & $<0.0001$ & 0.008 & 0.7 & $4.0 \pm 0.4$ & 0.2 & $12.6 \pm 1.8 / 29.8 \pm 4.8$ & 0.004 \\
\hline Visceral fat mass $(\mathrm{kg})$ & $0.7 \pm 0.1$ & $0.9 \pm 0.1$ & $1.3 \pm 0.1$ & $1.7 \pm 0.2$ & $<0.0001$ & 0.009 & 0.5 & $0.36 \pm 0.06$ & 0.1 & $40.5 \pm 5.8$ & 0.7 \\
\hline Visceral CT area & $21.3 \pm 2.0$ & $28.9 \pm 2.7$ & $43.1 \pm 6.2$ & $58.9 \pm 6.9$ & $<0.0001$ & 0.03 & 0.4 & $7.6 \pm 1.4 / 15.8 \pm 2.8$ & 0.02 & $41.4 \pm 5.8$ & 0.7 \\
\hline UB s.c. fat mass (kg) & $7.9 \pm 0.6$ & $9.4 \pm 0.5$ & $5.8 \pm 0.5$ & $7.9 \pm 0.5$ & 0.002 & 0.002 & 0.6 & $1.9 \pm 0.2$ & 0.2 & $22.0 \pm 2.6 / 41.0 \pm 7.3$ & 0.03 \\
\hline LB s.c. fat mass (kg) & $7.6 \pm 0.5$ & $9.0 \pm 0.6$ & $5.2 \pm 0.4$ & $6.9 \pm 0.5$ & $<0.0001$ & 0.003 & 0.7 & $1.6 \pm 0.1$ & 0.2 & $18.2 \pm 1.3 / 34.9 \pm 5.0$ & 0.006 \\
\hline
\end{tabular}

CT, computed tomography; LB, lower body; Pre, preoverfeeding; Post, postoverfeeding; S, sex; T, time; UB, upper body.

*Values for absolute or relative changes $(\Delta)$, which were not different $(P>0.5)$ between men and women. Values are means \pm SEM.

the average size of femoral fat cells was heterogeneous. For both women and men with smaller femoral adipocytes increased the average size of mature adipocytes, whereas average adipocyte size decreased (Fig. $1 B$ ) in men with femoral adipocytes larger than $\sim 0.35 \mu \mathrm{g}$ lipid per cell and in women with femoral adipocytes larger than $\sim 0.75 \mu \mathrm{g}$ lipid per cell. Histograms of adipocyte size from the woman and man with the greatest decreases in femoral adipocyte size are provided in Fig. S2. Firm statistical evidence for more than one population of mature adipocytes according to size was lacking. For both the woman (F2) and man (M2) with the greatest average

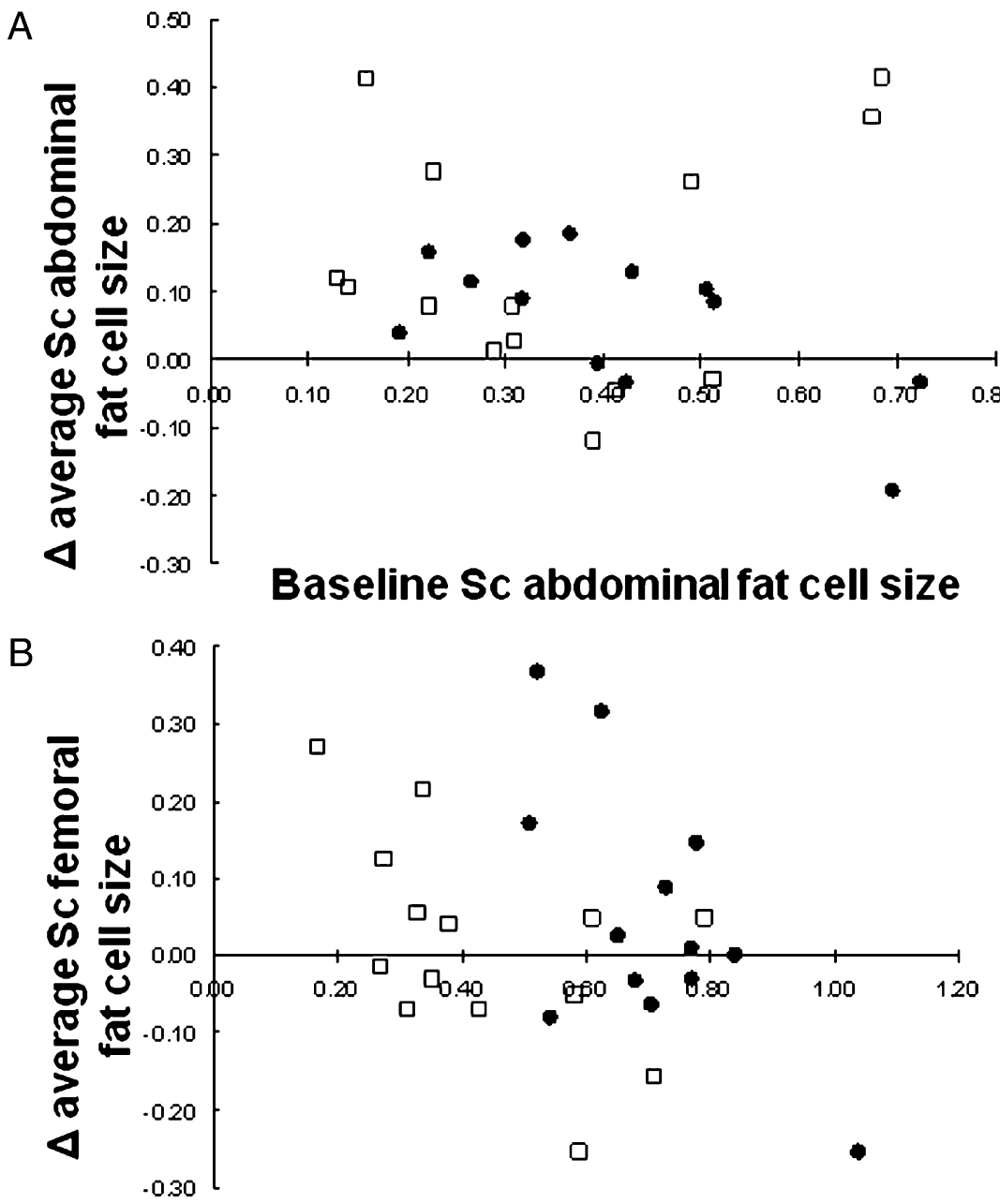

\section{Baseline Sc femoral fat cell size}

Fig. 1. Relationship between baseline mature adipocyte cell size ( $x$ axis) and change in adipocyte size ( $y$ axis) in response to weight gain. $\bullet$, data from women; $\square$, data from men. $(A)$ Abdominal s.c. adipocytes vs. change in abdominal adipocyte size. The relationship is significant for women $(r=-0.64, P=$ $0.02)$ but not for men $(r=0.23, P=0.43)$. (B) Femoral adipocytes vs. change in femoral adipocyte size. The relationship is significant for women $(r=-0.64, P=$ $0.02)$ and is of borderline significance for men $(r=-0.52, P=0.057)$. 
Table 2. Effect of overfeeding on regional adipose cellularity

\begin{tabular}{|c|c|c|c|c|c|c|}
\hline Variable & Preoverfeeding & Postoverfeeding & $\begin{array}{l}\text { Absolute } \\
\text { change }\end{array}$ & $\begin{array}{c}P \text { value } \\
\text { (absolute } \\
\text { change) }\end{array}$ & $\begin{array}{c}\text { Change } \\
\text { relative to } \\
\text { baseline }(\%)\end{array}$ & $\begin{array}{l}P \text { value } \\
\text { (relative } \\
\text { change) }\end{array}$ \\
\hline \multicolumn{7}{|c|}{ s.c. adipocyte size, $\mu \mathrm{g}$ lipid/cell ( $n=13$ women, 14 men) } \\
\hline Femoral & $0.57 \pm 0.04$ & $0.60 \pm 0.04$ & $0.03 \pm 0.03$ & 0.2 & $12 \pm 8$ & 0.07 \\
\hline \multicolumn{7}{|c|}{ s.c. adipocyte number, $\times 10^{9}(n=13$ women, 14 men $)$} \\
\hline Upper body & $20.2 \pm 1.3$ & $20.1 \pm 1.2$ & $-0.2 \pm 1.1$ & 0.8 & $3 \pm 5$ & 0.6 \\
\hline
\end{tabular}

Values are means \pm SEM.

decrease in femoral adipocyte size, there was a decrease in the proportion of larger cells and an increase in the proportion of midsized cells. Figs. S3 and S4 are histograms of adipocyte size in two men (M3 and M4) and two women (F3 and F4), respectively, with more typical changes in the size of abdominal and femoral fat cells. Our previous cross-sectional analysis of the relationship between s.c. adipocyte size and body fat distribution (12) showed that abdominal s.c. adipocyte size is associated inversely with lowerbody fat mass. In this longitudinal study, we confirmed that the relative fat gain in the lower body is a strong negative predictor of the change in abdominal s.c. adipocyte size (Fig. $2 B$ ).

Preadipocyte Kinetics at Baseline. Inherent differences in preadipocyte capacity for replication or susceptibility to apoptosis did not appear to explain the increased numbers of femoral but not abdominal s.c. fat cells in response to overfeeding. There are two preadipocyte subtypes, one capable of rapid and the other of limited replication (13). Regional differences in the proportions of these preadipocyte subtypes did not correlate with differences in the increase in the number of fat cells in the femoral and abdominal s.c. depots: $49 \pm 2 \%$ (mean \pm SEM) of abdominal s.c. cells and $51 \pm 2 \%$ of femoral s.c. cells were of the rapidly replicating subtype (n $=8$ females and 8 males; $P=0.5$ ). Treatment with increasing doses of TNF- $\alpha$ did not induce significantly more apoptosis in preadipocytes cultured from abdominal s.c. fat than in preadipocytes cultured from femoral s.c. fat (slope of 0,10 , and $50 \mathrm{ng}$ / $\mathrm{mL}$ TNF- $\alpha$-induced apoptosis was $45 \pm 4$ in abdominal vs. $55 \pm 4$ in femoral s.c. preadipocytes, $P=0.1$ ). However, abdominal and femoral s.c. preadipocytes differ in their inherent capacity for adipogenesis. Expression of the adipogenic transcription factors peroxisome proliferator-activated receptor- $\gamma 2(\operatorname{PPAR} \gamma 2)$ and $\mathrm{CCAAT} /$ enhancer-binding protein $\alpha(\mathrm{C} / \mathrm{EBP} \alpha)$, was significantly greater in abdominal than femoral s.c. preadipocytes $(P=0.0005$ and $P=0.03$, respectively). The ratio of PPAR $\gamma 2$ to total PPAR $\gamma$ also was greater in abdominal than femoral s.c. preadipocytes $(1.04 \pm 0.18$ vs. $0.17 \pm 0.03$, respectively, $P<0.0005)$.

\section{Discussion}

Our data challenge the contention that total number of body fat cells remains constant in adults (5). Using a longitudinal intervention model to study increases in body fat caused by overfeeding normal-weight adults, we found that gain of only $\sim 1.6 \mathrm{~kg}$ of lower-body fat resulted in the creation of $\sim 2.6$ billion new adipocytes within $8 \mathrm{wk}$. These findings clearly demonstrate that lowerbody fat-cell progenitors can develop rapidly into mature adipocytes in adult humans in response to overfeeding and that this response depends partially on sex and baseline adipocyte size. In a cross-sectional study, we found that number of leg fat cells is greater in overweight than in normoweight persons (12). Our current findings indicate that overweight individuals with more leg adipocytes may not have had greater numbers of adipocytes before they gained weight.

Unlike in femoral fat, the average abdominal s.c. adipocyte size, but not number, increased with an $\sim 2-\mathrm{kg}$ increase in upper-body fat. There is evidence that massive obesity is associated with abdominal s.c. adipocyte hyperplasia $(12,14,15)$. Thus, extensive, prolonged weight gain may be required before abdominal s.c. fatcell numbers increase, although our data suggest that normalweight women with relatively large abdominal s.c. adipocytes can recruit new mature adipocytes. Others have based the contention that fat-cell number is relatively fixed in adulthood on the analysis of abdominal s.c. fat cells (5). From cross-sectional data, it has been suggested that increased abdominal s.c. adipocyte number is contingent upon the adipocytes exceeding an average lipid content

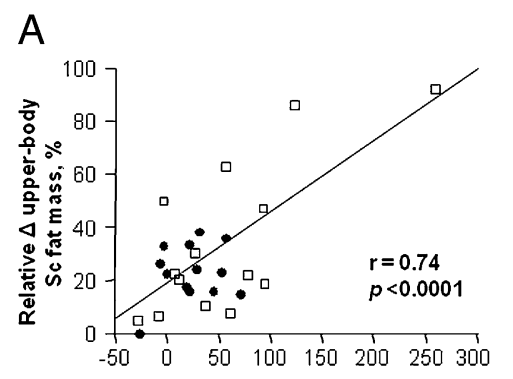

B

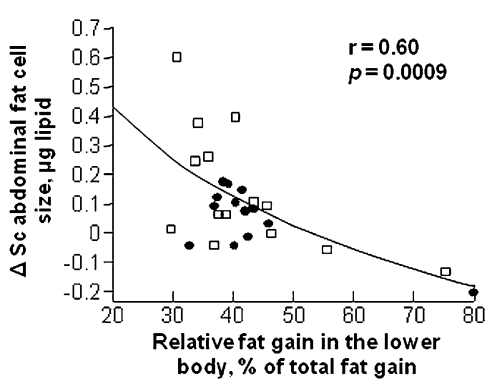

Fig. 2. Relationships between changes in regional s.c. fat gain and changes in adipocyte size. •, data from women; $\square$, data from men. ( $A$ ) Relative change $(\%)$ in upper-body fat mass $\{[$ (upper-body fat mass postoverfeeding - upper-body fat mass at baseline) $\div$ upper-body fat mass at baseline] $\times 100\}$ vs. relative change (\%) in abdominal s.c. adipocyte size $\{[$ (fat-cell size postoverfeeding - fat-cell size at baseline) $\div$ fat-cell size at baseline] $\times 100\}$. ( $B$ ) Change in abdominal s.c. fat-cell size vs. the relative amount of lower-body fat gain $\{$ (lower-body fat mass postoverfeeding - lower-body fat mass at baseline $) \div$ lowerbody fat mass at baseline] $\times 100\}$. Because the data were not normally distributed, regression analysis was performed using logarithmically transformed values of the relative increase in lower-body fat gain. The $r$ and $P$ values provided are from linear regression analysis of the transformed data; the depicted regression line is best fit using a power function. 
of $\sim 0.7-0.8 \mu \mathrm{g}$ per cell (16), a level close to that we observed in women. These findings are in accord with studies in experimental animals that indicate that, when adipocytes reach a critical volume, they secrete factors that recruit new adipocytes (17-19).

Our data suggest that the ability of healthy adults to expand lower-body fat via hyperplasia may prevent or delay abdominal s.c. fat-cell hypertrophy, presumably by sequestering the excess fat (Fig. 2B). An alternative mechanism is that some individuals display an overall adipose hyperplastic response to energy overload. This response was most evident in the women who had larger adipocytes at baseline, in whom the average size of mature adipocytes decreased in both depots with fat gain (Fig. $2 B$ and Fig. $\mathrm{S} 1$ ). This finding supports the recently reported link of high rates of adipogenesis with smaller size of abdominal s.c. adipocytes, lower waist-to-hip ratio, and more favorable metabolic profile (20). Regardless of the underlying mechanism, this finding is consistent with our previous observation that lower-body fat mass is a negative predictor of upper-body adipocyte size (12). Because abdominal s.c. adipocyte hypertrophy is a predictor for the development of insulin resistance and type 2 diabetes mellitus (21), this finding potentially provides an explanation for the purported beneficial health effects of the leg fat (2-4). Our observations are consistent with the overflow hypothesis, which implicates lowerbody fat as a primary adipose tissue compartment for expansion, the capacity of which may determine the degree to which secondary (upper-body s.c. and visceral) adipose tissue compartments grow during fat gain (22).

Newly formed mature adipocytes arise from preadipocytes, progenitors that are, for the most part, resident in fat depots (2326). Preadipocytes in abdominal s.c. fat are distinct from those in mesenteric or omental fat, differing in proliferative potential, replicative subtype abundance, capacity for adipogenesis, susceptibility to apoptosis, and gene-expression profiles $(6,13,27,28)$. These regional differences are retained for at least 40 cell generations in colonies derived from single cells. Therefore, we tested whether femoral s.c. preadipocytes are distinct from abdominal s.c. preadipocytes isolated from the same subjects, potentially contributing to the differences we found between these depots in fatcell size and number after overfeeding. We assayed in parallel the replicative potential of single, undifferentiated preadipocytes, the abundance of preadipocyte replicative subtypes, adipogenesis, and susceptibility to apoptosis in abdominal and femoral s.c. preadipocytes isolated from subjects before they began high caloric intake. Little difference was found in these properties, with the notable exception of the capacity for expressing adipogenic transcription factors. After $15 \mathrm{~d}$ of exposure to serum-free differentiation medium, the expression of the key adipogenic transcription factors PPAR $\gamma 2$ and $\mathrm{C} / \mathrm{EBP} \alpha$ was greater in abdominal than femoral preadipocytes. The importance of PPAR $\gamma 2$ for adipogenesis is well established $(29,30)$, and PPAR $\gamma$ is positively associated with fat-cell size in mice (31) and with obesity in humans (29). Inherent differences in fat-cell hyperplasia and, potentially, in the production of mediators that recruit new fat-cell development may, together with differences in circulation, nutrient supply, innervation, or local hormonal and paracrine factors, contribute to the distinct responses of different fat depots to high caloric intake. Future studies will be necessary to delineate these mechanisms.

We used a photomicrographic method (32) to measure the size of mature adipocytes for these studies. Advantages of this approach include the abilities to keep a permanent record of the measurement and to size a large number of cells, providing a better estimate of average adipocyte size. A disadvantage of this method is the need to select a lower limit for the cell size that will be measured to avoid counting multiple droplets within a single cell as separate cells (32). Because we used a lower limit of $35 \mu \mathrm{m}$, our approach does not include very small mature adipocytes (cells with a single lipid droplet $<35 \mu \mathrm{m}$ ), or early and late immature adipocytes (those with multiple lipid droplets $<10 \mu \mathrm{m}$ and $10-35 \mu \mathrm{m}$, respectively) that are counted by other methods (33). Although including cells with smaller diameters does not affect determination of average cell size (32), these smaller cells clearly are important to the understanding of adipose tissue biology (33).

Adipose tissue is highly plastic and can respond rapidly to changes in nutrient intake through fat-cell hypertrophy or hyperplasia, depending on the fat depot and fat-cell size. Increases in femoral adipose tissue mass can occur remarkably quickly through formation of new fat cells, even in adults. Capacity to store fat in lower-body depots is associated with reduced accumulation of fat in upper-body depots. Thus, greater capacity to form new lowerbody fat cells in response to overfeeding may confer protection against accumulation in upper-body and visceral depots, potentially mitigating adverse metabolic consequences of weight gain.

\section{Materials and Methods}

Subjects. The study was approved by the Mayo Clinic Institutional Review Board and informed, written consent was obtained from all participants. Twenty-eight volunteers [ 15 white men and 13 women (1 Asian, 1 black, and 11 white)] completed the study. Participants had a BMI $<26 \mathrm{~kg} / \mathrm{m}^{2}$ and had never been obese. Participants were not taking any medications except oral contraceptives, which four of the women were using. The women were permitted to participate in any phase of their menstrual cycle, largely because we have not found the phase of the menstrual cycle to be a confounding factor for adipose fatty acid storage (34) or release (35). Complete blood counts and chemistry panels were obtained and were normal in all subjects.

Protocol. Weight maintenance meals were provided by the Mayo Clinic General Clinical Research Center (GCRC) metabolic kitchen for $10 \mathrm{~d}$ before the overfeeding phase of the study to ensure constant macronutrient composition (50\% carbohydrate, $35 \%$ fat, and $15 \%$ protein) and stable weight, as previously described (36). Participants consumed at least one meal per day at the GCRC and were allowed to consume the remaining meals away from the GCRC, provided they returned the empty food containers. If weight changed by $\geq 1 \mathrm{~kg}$, the amount of food provided to participants was adjusted accordingly. Body composition was assessed by duplicate dual-energy X-ray absorptiometry (DXA) and computed tomography (CT) scans, as described below. After the weight-maintenance period, the volunteers were admitted to the GCRC at 1700 hours. The next morning, before breakfast, adipose tissue biopsies were obtained from the abdominal s.c. region, $\sim 5 \mathrm{~cm}$ lateral to the umbilicus, and from the anterior-lateral femoral s.c. region at the midthigh.

The participants then began the overfeeding phase of the study, with a goal of similar fat gain among subjects over $\sim 8 \mathrm{wk}$. The volunteers were instructed to increase their overall food intake by eating until they were more full than usual. In addition, they were provided with supplemental food from the GCRC metabolic kitchen. The supplements consisted of a choice of an ice cream shake (402 kcal, 40\% fat), a king-sized Snickers bar (510 kcal) (Mars Inc.), and Boost Plus (360 kcal/8 oz) (Nestle Nutrition). Body weight was measured at least $5 \mathrm{~d} / \mathrm{wk}$ to assess weight gain. The rate of fat gain relative to weight gain was determined by a repeat DXA $\sim 4$ wk into the overfeeding period. We used these data to project the amount of body weight each volunteer would need to gain to achieve the desired fat gain. The amount of supplemental food provided to study participants was adjusted as needed and ranged from one to four supplements per day.

After achieving their target weight gain ( $~ 8 \mathrm{wk})$, the volunteers once again received $10 \mathrm{~d}$ of meals from the GCRC metabolic kitchen with the same macronutrient distribution as in the pre-weight-gain interval to stabilize weight. The energy content of these meals was greater than the original weight-maintenance intake. The amount of food each participant needed to consume was determined by the energy content of the supplements they had required during the overfeeding period combined with their preoverfeeding weight-maintenance diet. Weights were measured daily to ensure each volunteer was not losing any of the weight he or she had gained. The volunteers then were readmitted to the GCRC, where identical procedures were followed and repeat adipose biopsies were obtained.

Body Composition. Total body fat, leg fat, and total fat-free mass (FFM) were measured in duplicate with DXA (DPX-IQ; Lunar Radiation) at visit 1 and at visit 2; the DXA in the middle of the overfeeding period was a single scan. The average values of the two scans at each visit were used to assess total and regional body composition. Visceral fat was determined at visit 1 and visit 2 using three CT images obtained at the levels of $L_{2-3}, L_{3-4}$, and $L_{4-5}$ (the av- 
erage of the three slices used) in combination with DXA abdominal fat analysis in duplicate (37)

Processing of Fat Tissue. Adipose tissue collected from abdominal and femoral s.c. sites was collagenase (type II C-6885; Sigma)-digested for 60 min in a $37^{\circ} \mathrm{C}$ water bath, and the cells were fractionated by centrifugation at $350 \times \mathrm{g}$. Adipocytes in the top layer were used for fat-cell sizing. The cellular pellet was reconstituted in erythrocyte lysis buffer $\left(0.154 \mathrm{M} \mathrm{NH}_{4} \mathrm{Cl}, 10 \mathrm{mM} \mathrm{KHCO}_{3}\right.$, $1 \mathrm{mM}$ EDTA) for $5 \mathrm{~min}$ at room temperature. For the baseline studies, the adipose tissue SV cell suspension was cultured in DMEM/Ham's F-12 medium (1:1) (Invitrogen) enriched with 10\% FBS. After 18-24 h, cells were trypsinized and replated to deplete macrophages, as described previously (38). Preadipocytes were grown until confluence, trypsinized, and frozen in $\alpha M E M$ containing $45 \%$ FBS and $5 \%$ DMSO until subsequent in vitro assessment of preadipocyte cell kinetics. Recovery after freezing was $~ 70 \%$ and was not affected by fat depot origin.

Fat-Cell Size and Number. The size of the isolated fat cells was measured using digital photomicrographs and an automated software program as previously described (32). We measured an average of 550 cells per site to calculate average adipocyte size, and each size histogram was assessed for more than one cell-size population. We estimated the likelihood that there is more than one population of adipocytes with diameters $>35 \mu \mathrm{M}$ using the Hormone Pulsatility Analysis Software from the University of Virginia Center for Biomathematical Technology (http://mljohnson.pharm.virginia.edu/biomath-ctr/biomath-home. $\mathrm{html}$ ). Correctly identifying "peaks" of adipocyte populations on histograms is a statistical challenge similar to identifying pulses of hormone secretion. The program discriminates between random variations in values across intervals (in this case bin size) and true peaks. We used the program to identify the number of peaks to infer the number of discrete populations of cells. Regional adipocyte number was calculated by dividing the regional fat mass by the mean lipid content per adipocyte from the respective depot.

Preadipocyte Kinetics. Proliferation and abundance of preadipocyte subtypes was assessed in cloned preadipocytes by DNA quantitation using CyQuant dye (Molecular Probes, Inc.) as previously described (13). Abdominal and femoral s.c. preadipocytes were differentiated in duplicate for $15 \mathrm{~d}$ in serum-free medium supplemented with $0.1 \mu \mathrm{M}$ dexamethasone, $0.5 \mu \mathrm{M}$ insulin, $0.2 \mathrm{nM}$ triiodothyronine, $0.5 \mu \mathrm{M}$ rosiglitazone, $20 \mu \mathrm{M}$ fetuin, antibiotics, and $540 \mu \mathrm{M}$ methylisobutylxanthine (39), and total RNA was extracted with TRIzol (Invitrogen). For exclusion of genomic DNA, $10 \mu \mathrm{g}$ of total RNA was treated with DNase I (Ambion) for $1 \mathrm{~h}$ at $37{ }^{\circ} \mathrm{C}$. RNA integrity and quality was assessed by electrophoresis. One microgram of RNA was reverse-transcribed

1. Reaven GM (1988) Banting lecture 1988. Role of insulin resistance in human disease Diabetes 37:1595-1607.

2. Snijder MB, et al. (2004) Independent and opposite associations of waist and hip circumferences with diabetes, hypertension and dyslipidemia: The AusDiab Study. In $J$ Obes Relat Metab Disord 28:402-409.

3. Van Pelt RE, Jankowski CM, Gozansky WS, Schwartz RS, Kohrt WM (2005) Lower-body adiposity and metabolic protection in postmenopausal women. J Clin Endocrino Metab 90:4573-4578.

4. Snijder MB, et al.; Hoorn study (2004) Trunk fat and leg fat have independent and opposite associations with fasting and postload glucose levels: The Hoorn study. Diabetes Care 27:372-377.

5. Spalding KL, et al. (2008) Dynamics of fat cell turnover in humans. Nature 453:783-787.

6. Tchkonia T, et al. (2002) Fat depot origin affects adipogenesis in primary cultured and cloned human preadipocytes. Am J Physiol Regul Integr Comp Physiol 282: R1286-R1296.

7. Kirkland JL, Tchkonia T, Pirtskhalava T, Han J, Karagiannides I (2002) Adipogenesis and aging: Does aging make fat go MAD? Exp Gerontol 37:757-767.

8. Karagiannides I, et al. (2001) Altered expression of C/EBP family members results in decreased adipogenesis with aging. Am J Physiol Regul Integr Comp Physiol 280 R1772-R1780.

9. Tchoukalova YD, et al. (2010) Sex- and depot-dependent differences in adipogenesis in normal-weight humans. Obesity (Silver Spring), 10.1038/oby.2010.56.

10. Romanski SA, Nelson R, Jensen MD (2000) Meal fatty acid uptake in adipose tissue: Gender effects in non-obese humans. Am J Physiol 279:E455-E462.

11. Martin ML, Jensen MD (1991) Effects of body fat distribution on regional lipolysis in obesity. J Clin Invest 88:609-613.

12. Tchoukalova YD, et al. (2008) Subcutaneous adipocyte size and body fat distribution. Am J Clin Nutr 87:56-63.

13. Tchkonia T, et al. (2005) Abundance of two human preadipocyte subtypes with distinct capacities for replication, adipogenesis, and apoptosis varies among fat depots. Am J Physiol 288:E267-E277.

14. Tchoukalova $Y$, Koutsari C, Jensen M (2007) Committed subcutaneous preadipocytes are reduced in human obesity. Diabetologia 50:151-157. into cDNA using a Taqman One-Step RT-PCR kit (\#4309169; Applied Biosystems) in $100 \mu \mathrm{L}$ reaction mixture. Real-time PCR was carried out using TaqMan Fast Universal PCR Master Mix $2 \times$ in a 7500 Fast Real-Time PCR System (Applied Biosystems). In brief, $10 \mu \mathrm{L}$ of Fast PCR Master Mix were combined with $5 \mu \mathrm{L}$ of CDNA, $1 \mu \mathrm{L}$ of the appropriate TaqMan single-gene assay (total PPAR $\gamma$ : Hs00234592; PPAR $\gamma 2$ : Hs0111510; C/EBP $\alpha$ : Hs00269972; all from Applied Biosystems) and $4 \mu \mathrm{L}$ water. Following initial incubation for $20 \mathrm{~s}$ at $95{ }^{\circ} \mathrm{C}$, PCR was carried out for 40 cycles for $3 \mathrm{~s}$ at $95{ }^{\circ} \mathrm{C}$ and $30 \mathrm{~s}$ at $60{ }^{\circ} \mathrm{C}$. RNA was analyzed by relative quantification using TATA box-binding protein RNA as an internal control (5'-FAM/3'-MGB probe, 4333769F; Applied Biosystems). The ratio of regional mRNA levels to the sum of mRNA levels from both depots signified the regional relative gene expression.

To assess apoptosis, confluent cultures grown in serum-containing medium were treated with 0,10 , or $50 \mathrm{ng} / \mathrm{mL}$ recombinant human TNF- $\alpha$ for $4 \mathrm{~h}$. Cells were stained with bisbenzimide and examined for fragmented and/or condensed nuclei (morphological features of apoptosis) by fluorescence microscopy (40). The mean percentage of such nuclei relative to all the nuclei in at least four fields was determined. The slope of the mean apoptotic response of preadipocyte cultures to the increasing doses of TNF- $\alpha$ was used as an index of the preadipocyte sensitivity to apoptotic insult.

Statistical Analysis. Data were analyzed using SAS v. 9.1.3 (SAS Institute Inc.) All values are expressed as mean \pm SEM. We used repeated-measures ANOVA to test the effects of time (pre- and postoverfeeding), sex (males, females), and the sex $\times$ time interaction on body composition and fat distribution and a paired $t$ test to test the effect of overfeeding on adipocyte size and number. Preadipocyte cell kinetics, measured at baseline, were analyzed by one-way ANOVA using depot as a fixed effect. We performed simple linear regression analysis to analyze the relationship between the change in regional adipocyte size and the change in upper- and lower-body s.c. fat mass; for the latter, we used a logarithmic transformation of the values to account for its curvilinear relation with the change in fat-cell size. $P<0.05$ was considered statistically significant for all these tests.

ACKNOWLEDGMENTS. We thank Deborah Harteneck, Jessica Eastman, Caro Siverling, and the staff of the Mayo Clinic General Clinical Research Center for technical assistance; Monica Davis for editorial assistance; and Xiaobing Fang from Pennington Biomedical Research Center for statistical analyses. This research was supported by National Institutes of Health Grants DK45343 (to M.D.J.), DK50456 (to M.D.J.), and RR00585 (to M.D.J.); US Public Health Service Grant AG13925 (to J.L.K.); the Noaber Foundation; the Mayo Foundation; and, in part, the Intramural Research Program of the National Institute of Diabetes and Digestive and Kidney Diseases, National Institutes of Health.

15. Drolet $R$, et al. (2008) Hypertrophy and hyperplasia of abdominal adipose tissues in women. Int J Obes (Lond) 32:283-291.

16. Krotkiewski M, Björntorp P, Sjöström L, Smith U (1983) Impact of obesity on metabolism in men and women. Importance of regional adipose tissue distribution. J Clin Invest 72:1150-1162.

17. Faust IM, Johnson PR, Stern JS, Hirsch J (1978) Diet-induced adipocyte number increase in adult rats: A new model of obesity. Am J Physiol 235:E279-E286.

18. DiGirolamo M, Fine JB, Tagra K, Rossmanith R (1998) Qualitative regional differences in adipose tissue growth and cellularity in male Wistar rats fed ad libitum. Am Physiol 274:R1460-R1467.

19. Marques BG, Hausman DB, Martin RJ (1998) Association of fat cell size and paracrine growth factors in development of hyperplastic obesity. Am J Physiol 275: R1898-R1908.

20. Arner E, et al. (2010) Adipocyte turnover: Relevance to human adipose tissue morphology. Diabetes 59:105-109.

21. Weyer C, Foley JE, Bogardus C, Tataranni PA, Pratley RE (2000) Enlarged subcutaneous abdominal adipocyte size, but not obesity itself, predicts type II diabetes independent of insulin resistance. Diabetologia 43:1498-1506.

22. Sniderman AD, Bhopal R, Prabhakaran D, Sarrafzadegan N, Tchernof A (2007) Why might South Asians be so susceptible to central obesity and its atherogenic consequences? The adipose tissue overflow hypothesis. Int J Epidemiol 36:220-225.

23. Crossno JT, Jr., Majka SM, Grazia T, Gill RG, Klemm DJ (2006) Rosiglitazone promotes development of a novel adipocyte population from bone marrow-derived circulating progenitor cells. J Clin Invest 116:3220-3228.

24. Koh YJ, et al. (2007) Bone marrow-derived circulating progenitor cells fail to transdifferentiate into adipocytes in adult adipose tissues in mice. J Clin Invest 117:3684-3695.

25. Scadden DT (2007) The weight of cell identity. J Clin Invest 117:3653-3655.

26. Tang W, et al. (2008) White fat progenitor cells reside in the adipose vasculature. Science 322:583-586.

27. Tchkonia T, et al. (2006) Fat depot-specific characteristics are retained in strains derived from single human preadipocytes. Diabetes 55:2571-2578.

28. Tchkonia T, et al. (2007) Identification of depot-specific human fat cell progenitors through distinct expression profiles and developmental gene patterns. Am J Physio Endocrinol Metab 292:E298-E307. 
29. Sewter C, Blows F, Considine R, Vidal-Puig A, O'Rahilly S (2002) Differential effects of adiposity on peroxisomal proliferator-activated receptor gamma1 and gamma2 messenger ribonucleic acid expression in human adipocytes. $J$ Clin Endocrinol Metab 87:4203-4207.

30. Sewter CP, Blows F, Vidal-Puig A, O'Rahilly S (2002) Regional differences in the response of human pre-adipocytes to PPARgamma and RXRalpha agonists. Diabetes 51:718-723.

31. Kubota N, et al. (1999) PPAR $\gamma$ mediates high-fat diet-induced adipocyte hypertrophy and insulin resistance. Mol Cell 4:597-609.

32. Tchoukalova YD, Harteneck DA, Karwoski RA, Tarara J, Jensen MD (2003) A quick, reliable, and automated method for fat cell sizing. J Lipid Res 44:1795-1801.

33. McLaughlin T, et al. (2007) Enhanced proportion of small adipose cells in insulin resistant vs insulin-sensitive obese individuals implicates impaired adipogenesis. Diabetologia 50:1707-1715.

34. Uranga AP, Levine J, Jensen M (2005) Isotope tracer measures of meal fatty acid metabolism: Reproducibility and effects of the menstrual cycle. Am J Physiol Endocrinol Metab 288:E547-E555
35. Heiling VJ, Jensen MD (1992) Free fatty acid metabolism in the follicular and luteal phases of the menstrual cycle. J Clin Endocrinol Metab 74:806-810.

36. Levine JA, Eberhardt NL, Jensen MD (1999) Role of nonexercise activity thermogenesis in resistance to fat gain in humans. Science 283:212-214.

37. Jensen MD, Kanaley JA, Reed JE, Sheedy PF (1995) Measurement of abdominal and visceral fat with computed tomography and dual-energy x-ray absorptiometry. Am J Clin Nutr 61:274-278.

38. Djian P, Roncari AK, Hollenberg CH (1983) Influence of anatomic site and age on the replication and differentiation of rat adipocyte precursors in culture. $J$ Clin Invest 72: 1200-1208.

39. Hauner H, Petruschke T, Russ M, Röhrig K, Eckel J (1995) Effects of tumour necrosis factor alpha $(T N F \alpha)$ on glucose transport and lipid metabolism of newlydifferentiated human fat cells in cell culture. Diabetologia 38:764-771.

40. Deckwerth TL, Johnson EM, Jr (1993) Temporal analysis of events associated with programmed cell death (apoptosis) of sympathetic neurons deprived of nerve growth factor. J Cell Biol 123:1207-1222. 